\title{
Formação continuada com professores de educação infantil de escolas municipais de ensino fundamental de Santa Maria: o brincar e as experiências corporais
}

\author{
Continued education for teachers of early childhood education of municipal elementary schools \\ in Santa Maria: games and bodily experiences
}

Formación continua con maestros de educación infantil de las escuelas primarias municipales de Santa Maria: juego y las experiencias corporales

\author{
Amanda Beatriz Eich ${ }^{\mathrm{I}}$ Juliana Picolotto ${ }^{\mathrm{II}}$, Maria Cecília da Silva Camargo ${ }^{\mathrm{III}}$
}

\begin{abstract}
Resumo
Este texto resulta da análise do processo de formação continuada de professoras de Educação Infantil (EI) de Escolas Municipais de Ensino Fundamental de Santa Maria - RS, em projeto de extensão da Universidade Federal de Santa Maria, cujo foco foi o brincar e as experiências corporais na infância. Trabalhou-se em ambiente virtual, com uso de narrativas produzidas pelas professoras participantes, articulando-se memórias de suas experiências na infância às suas práticas pedagógicas com a EI e concepções de infância que orientam sua docência. As videoconferências, rodas de conversa e produção escrita pautaram-se em relação dialógica, culminando em um seminário virtual, no qual foram compartilhadas experiências pedagógicas e produções resultantes da formação. Constatou-se uma repercussão sobre o processo formativo de licenciandos, mestrandos e docentes que atuaram na organização e realização do projeto, para além das professoras participantes.
\end{abstract}

Palavras-chave: Formação Continuada; Educação Infantil; Brincar; Experiências Corporais

\begin{abstract}
This work results from the analysis of the process of continued teacher education for teachers of Early Childhood Education (ECE) of Municipal Elementary Schools in Santa Maria, Rio Grande do Sul, Brazil, in an extension project of the Universidade Federal de Santa Maria in which the focus was games and bodily experiences during childhood. The work was carried out in a virtual environment, using narratives produced by the participating teachers, linking memories of their childhood experiences with their pedagogical practices with ECE and childhood concepts that guide their teaching. The videoconferences, roundtables and written production were guided by a dialogical relationship, culminating in a virtual seminar in which pedagogical experiences and productions resulting from the training were shared. The project also affected the training process of undergraduate and master's degree students and teachers who worked in its organization and implementation, in addition to the participating teachers.
\end{abstract}

Keywords: Continued Education; Early Childhood Education; Games; Bodily Experiences

\footnotetext{
${ }^{\text {I } U n i v e r s i d a d e ~ F e d e r a l ~ d e ~ S a n t a ~ M a r i a ~-~ U F S M ~-~ E n d e r e c ̧ o: ~ A v . ~ R o r a i m a ~ n o ~} 1000$ Cidade Universitária Bairro - Camobi, Santa Maria - RS, CEP: $97105-900$ e-mail: amandabeatrizeich@gmail.com

II Universidade Federal de Santa Maria - UFSM - e-mail: juuliana_picolootto@ outlook.com

${ }^{\mathrm{II}}$ Universidade Federal de Santa Maria - UFSM - e-mail: mceciliacg6@ hotmail.com
} 


\section{Resumen}

Este artículo tiene como objetivo analizar el proceso de formación continua en forma virtual para maestros de educación infantil (EI) en escuelas primarias municipales de Santa María - RS de modo colaborativa entre la Secretaría Municipal de Educación y la Universidad Federal de Santa María. El enfoque principal de esta formación es el juego y las experiencias corporales en la niñez. Las narrativas formativas fueron producidas por los maestros participantes a partir de memorias de sus vivencias infantiles, articulándolas con sus prácticas pedagógicas y concepciones de niño y niñez que orientan su enseñanza. Durante el proceso se llevaron a cabo conferencias, discusiones, reflexiones, conversaciones, a través de una relación dialógica y la culminación fue el seminario virtual, donde los participantes tuvieron la posibilidad de compartir y sistematizar la producción de los conocimientos adquiridos. Fue encontrado impacto en el proceso de formación de los estudiantes de pregrado, maestría y docentes que trabajaron en la organización e implementación del proyecto, además de los docentes participantes.

Palabras clave: Formación continua; Educación infantil; Jugar; Experiencias corporales

\section{Introdução}

A importância da formação continuada no percurso profissional docente e como forma de assegurar o desenvolvimento profissional tem sido propalada por diferentes autores, a partir de distintas perspectivas (DAY, 2001; FREITAS, 2011; IMBERNÓN, 2001; JOSSO, 2004). Um dos aspectos centrais, para algumas perspectivas, é a centralidade na escola e nas experiências pedagógicas dos(as) professores(as), como é o caso de Marques (1992), o qual defende que seja esse o lócus privilegiado das ações de formação continuada, e acrescenta que as experiências são vividas cotidianamente na profissão. É sob essa condição da concretude das experiências que “[...] as determinações específicas dos problemas devem ser analisadas e entendidas, rearticulando-se as relações entre os componentes da situação, os passos do discurso argumentativo e a execução das operações exigidas pela melhor solução possível" (MARQUES, 1992, p.194).

De outra parte, ações de formação de professores em ambiente virtual (AV) têm se multiplicado por meio de diferentes propostas, podendo manter a centralidade nas experiências dos(as) participantes, tanto no processo de formação inicial (BIANCHI, HATJE, 2007; ROSA, 2006), quanto no de formação continuada (OLIVEIRA, BUENO, 2013; SCHEID, MEURER, 2011). O uso do AV abre novas perspectivas para a formação continuada de professores, propiciando espaços de interação e trocas de experiências por meio de diferentes ferramentas de tecnologia educacional que flexibilizam a participação, podendo até mesmo ampliar, do ponto de vista geográfico, o público integrante. Não se trata de exaltar as formações em AV, mas de mencionar sua importância e, em alguns casos, suas vantagens, 
podendo até mesmo combinar módulos em AV com encontros presenciais, como na experiência relatada por Camargo, Guimarães e Mello (2020).

Diante do quadro de crise sanitária e da pandemia de COVID 19, o ano de 2020 foi marcado pela suspensão de atividades presenciais, nas diferentes redes de ensino, atingindo diferentes níveis da educação no país e no mundo. O ensino remoto tornou-se a opção e, mais do que nunca, as formações continuadas de professores em AV ganharam importância, não apenas na instrumentalização para o uso de tecnologias educacionais remotas, mas também como alternativa para outras temáticas que viessem a ser abordadas.

Nesse cenário, foi concebida e realizada a "Formação continuada com professoras de turmas de Educação Infantil (EI) de escolas municipais de Ensino Fundamental de Santa Maria (EMEF-SM) - O brincar e as experiência corporais", a partir de um projeto de extensão vinculado ao Centro de Educação Física e Desportos da Universidade Federal de Santa Maria (CEFD/UFSM), em uma relação colaborativa com a Secretaria Municipal de Educação de Santa Maria - RS.

A Base Nacional Comum Curricular (BRASIL, 2018) reafirma os eixos propostos nas Diretrizes Curriculares Nacionais para a Educação Infantil (BRASIL, 2013), as interações e as brincadeiras, visando assegurar às crianças

“[...] as condições para que as crianças aprendam em situações nas quais possam desempenhar um papel ativo em ambientes que as convidem a vivenciar desafios e a sentirem-se provocadas a resolvê-los podendo construir significados sobre si, os outros e o mundo social e natural (BRASIL, 2018). Conviver, brincar, participar, explorar, expressar e conhecer-se são os direitos de aprendizagem previstos e que devem materializar-se a partir de uma "intencionalidade educativa".

O brincar é defendido por Sarmento (2016) como um direito das crianças e que, segundo o autor, devem ser assegurado na Educação Infantil, tanto no sentido de um brincar espontâneo, quanto de ações mediadas pelo(a) educador(a), no sentido de ampliar o repertório de brincadeiras delas; posição similar à de Evedove, Assis e Ayoub (2019). É por meio do brincar e do "se movimentar" que a criança toma consciência de si e do mundo que a rodeia (KUNZ, 2002), constituindo-se como a fonte mais rica de experiências na infância.

As experiências corporais e de movimento são intrínsecas ao brincar da essência da criança, conforme expressam Costa e Kunz (2013, p.52) 
O "brincar e Se-Movimentar" é o mundo de vida mais essencial da criança, assim, é preciso compreender com maior profundidade o ser crianças, ou seja, compreender seu envolvimento corporal com o mundo, com os outros e consigo mesma. Nesse sentido, o "Brincar e SeMovimentar" é uma maneira profunda de engajar-se corporalmente com o mundo, com o outro e consigo mesma.

Os mesmos autores tecem críticas ao uso de formas de brincar como recurso pedagógico voltadas à aquisição de aprendizagens que perspectivam a formação de um adulto produtivo no futuro. Na direção contrária, defendem o brincar e o "se movimentar" como ações presentes, formas de se expressar, de ser e estar no mundo, de forma dialógica e que possibilite à criança atribuir sentidos. Trata-se, portanto, da centralidade do brincar como condutor de múltiplas experiências do mundo por meio do corpo e do movimento.

Em convergência com esse entendimento da centralidade do brincar na infância, perpassado pelas experiências de corpo e de movimento, foi concebido o projeto de formação continuada que passamos a descrever e a discutir na continuidade do texto.

\section{Estrutura, Conteúdo e Forma}

A condição de suspensão de atividades presenciais, conforme já mencionado, impôs a necessidade de que fosse criada e organizada uma formação em AV. A experiência vivenciada pela autora do projeto (CAMARGO, GUIMARÃES, MELLO, 2020) foi tomada como ponto de partida para a sua concepção, neste caso, planejada integralmente em AV.

A experiência vivida na formação continuada e o cuidado na documentação ao longo do processo instigou-nos a produzir esse texto. Daltro e Faria (2019), p. 224, destacam a importância do relato de experiência como uma das formas de produção "de narrativa científica, especialmente no campo das pesquisas capazes de englobar processos e produções subjetivas", o que parece compatível com o processo de formação analisado neste texto. A documentação produzida - textos, vídeos, imagens e registros do processo - foram objeto de análise cuidadosa, com atenção para o contexto de sua produção, conforme preconizado por Cellard (2008) para esse procedimento. A esse procedimento de análise documental, agregamos considerações elaboradas a partir do processo reflexivo nas reuniões preparatórias do Grupo Pátio $^{2}$, quando discutíamos a experiência da formação continuada.

${ }^{1}$ De acordo com Kunz (2015) o conceito de "Brincar e Se-Movimentar" proposto por ele, assenta-se na teoria do "semovimentar humano" que o autor discute em suas produções desde $1991 \mathrm{e}$, de outra parte, procura problematizar a presença do "brincar didatizado", de caráter utilitarista, muito presente na literatura pertinente ao tema.

${ }^{2}$ Grupo Pátio de Estudos Qualitativos sobre formação de professores e prática pedagógica em Educação Física. 
Participaram da formação a coordenadora do projeto, duas graduandas do curso de Educação Física (licenciatura), quatro mestrandos(as), integrantes do Grupo Pátio; duas assessoras da Secretaria Municipal de Educação (Educação Infantil) e o público-alvo do projeto, 75 professoras que atuam na EI em Escolas Municipais de Ensino Fundamental. Inicialmente, um número significativo de professoras se inscreveu e demonstrou interesse em participar do evento. No decorrer do processo, foram constatadas variações na participação das atividades desenvolvidas. Diante do fato ocorrido, surgiram questionamentos sobre essa oscilação. Teriam ocorrido por resistência à escrita das narrativas? Por problemas de conexão com a internet? Pela dificuldade no uso de ferramentas virtuais? O tempo exigido para a realização das atividades seria insuficiente? Impossibilidade em conciliar as atividades profissionais, familiares com a formação continuada?

Os encontros ocorreram em ambiente virtual com uso da plataforma Google Meet. O aplicativo utilizado para tirar e dar orientações foi o WhatsApp, auxiliando e estimulando as professoras a escrever e enviar as narrativas por meio de tutoriais e templates disponibilizados para a realização das atividades. $\mathrm{O}$ conjunto de ações combinou palestras, discussões, rodas de conversas, culminando em seminário virtual, que aconteceu no mês de dezembro, cujos participantes tiveram a possibilidade de compartilhar e sistematizar a produção de conhecimento elaborado.

Ao longo da formação, foram feitas provocações por meio de textos, imagens e palestras, com o objetivo de mobilizar as professoras a produzir narrativas formativas de memórias de suas vivências na infância, articulando-as com suas práticas pedagógicas com a EI e com concepções de criança e infância que orientam sua docência. As diferentes etapas e ações convergiam na intenção de levar as professoras ao que Josso (2004) denomina como "caminhar para si” no processo de construção das narrativas.

A proposição dos encontros articulados à produção de narrativas escritas, fundamentou-se no caráter dialógico e reflexivo desse processo (BOLÍVAR, 2002; CÔCO, 2014) visando emergir as relações entre as experiências pessoais em torno do brincar e a constituição das práticas pedagógicas que essas professoras realizam com a EI, procurando aguçar o olhar para a centralidade do corpo e do movimento no brincar infantil (MELLO et al., 2016).

\section{Análise do processo - o caminho percorrido}

Apesar das dificuldades encontradas no decorrer do processo, foi possível observar o protagonismo das professoras envolvidas com uma participação efetiva e dialógica, possibilitando trocas 
de experiências, reflexões, indagações e reelaboração de sentidos conferidos às experiências docentes, ao brincar e às experiências corporais. Ao apresentar o caminho percorrido, retomamos algumas descrições de etapas que constituíram a formação para que a discussão se tornasse compreensível ao(à) leitor(a).

A formação continuada realizou-se em três momentos principais: videoconferências, leitura e discussão de textos e produção de narrativas. As videoconferências contaram com palestrantes de várias cidades do Brasil, o que contribuiu muito para as discussões do grupo e os textos serviram como apoio ao pensar o brincar e as experiências corporais na EI. No entanto, destacamos a produção de narrativas como um espaço de expressão de sentimentos, representações, percepções, avanços, recuos e crenças que emergem no processo de formação e autoformação (SOUZA, 2006).

A abertura da formação teve como convidado o Prof. Dr. Rodrigo Lema Del Rio Martins, em videoconferência intitulada: "A experiência do brincar - um olhar a partir do corpo e movimento". A videoconferência contou com a presença de todas as inscritas que interagiram com o palestrante por meio da ferramenta do chat, o que reverberou bastante entre as participantes e, notadamente, entre os integrantes do Grupo Pátio, sendo retomado em discussões nas reuniões do grupo. Com isso, notamos que o processo formativo, embora tivesse como público-alvo o professorado das EMEF-SM, viria a incidir fortemente sobre todas as pessoas envolvidas, potencializando a formação de jovens pesquisadores(as) do Grupo Pátio.

Com a intenção de provocar reflexões sobre as vivências na infância das professoras e posteriormente escrever suas narrativas, foram disponibilizados textos, quadrinhos e documentos curriculares distribuídos ao longo de três unidades. Na Unidade I: Experiências de brincar: das memórias da infância à prática docente, foi disponibilizado o texto "Elaboração de Memória Profissional I" (CAPARRÓZ, 2009). A leitura indicada teve a intenção de auxiliá-las na compreensão da proposta da formação e na elaboração das narrativas.

O autor remete a significativas reflexões acerca da importância do ato de escrever. Sua análise social destaca a tradição da oralidade, em detrimento da comunicação escrita, principalmente quando falamos de nossas experiências. Acrescenta que este processo é um ato individualizado, podendo causar incômodo para algumas pessoas e, para outras, ser um momento de satisfação e intensa alegria. Leitura e a escrita estão, muitas vezes, relacionadas a tarefas escolares e/ ou deveres a serem cumpridos, caracterizando-se por uma ação reprodutiva do momento. Desse modo, entendemos que a escrita de modo reflexivo não surge repentinamente, e sim, de forma gradual, que exige um esforço de sistematização na tentativa do erro e acerto (CAPARRÓZ, 2009). 
Prosseguindo na Unidade I, foi proposta a leitura do texto "Na Escola Infantil todo mundo brinca se você brinca" (DORNELLES, 2011), e a interpretação de um quadrinho com o personagem "Armandinho", de autoria de Alexandre Beck, com a intenção de provocar um pensamento crítico sobre as experiências com o brincar. O texto faz refletir sobre o tempo e o espaço do brincar para as crianças, questionando sobre o papel de pais e educadores ao observarmos como e quando as crianças brincam. Segundo a autora, "todo mundo brinca se você brinca", mas quem se dedica a ver e entender o que as crianças brincam e como brincam? Ouvir sobre o que falam, cantam e dançam? O interesse pelo brincar se manifesta sempre que lhes for dado o espaço e o tempo necessário para isso e deve ser assegurado propiciando formas livres de brincar, apenas pelo prazer que propicia (DORNELLES, 2011). O texto escolhido vai ao encontro da perspectiva do "Brincar e Se-Movimentar" (COSTA, KUNZ. 2013; KUNZ, COSTA, 2015), que destaca a imersão da criança no brincar, entregando-se integralmente a essa ação, vivida corporalmente por ela.

Após as leituras da Unidade I, as professoras receberam a primeira atividade com a proposta de escrever um relato sobre as experiências que recordam, procurando descrever estas experiências acompanhadas dos sentimentos e sensações que fazem parte dessas lembranças. As leituras realizadas poderiam remetê-las a pensar sobre o brincar e seus múltiplos significados, auxiliando na compreensão da proposta da formação e a centralidade da escrita no processo.

Por meio da escrita das narrativas formativas, as professoras tiveram a oportunidade de revisitar suas memórias, sentimentos, emoções e sensações, proporcionando uma autoformação, refletindo sobre suas práticas e ressignificando seus saberes. A interlocução com essas narrativas, para integrantes do grupo Pátio, exigiu uma escuta sensível ao que foi expresso nas produções e possibilitou um pensamento crítico-reflexivo, reverberando no processo formativo, tanto de professores já atuantes quanto de licenciandos que atuaram no projeto.

Iniciando a Unidade II - foram disponibilizados textos sobre os documentos curriculares para a Educação Infantil (RCNEI, DCNEI e BNCC). O texto "Base Nacional Comum Curricular para a Educação Infantil: entre desafios e possibilidades dos campos de experiência educativa" (SIMIANO; SIMÃO, 2016), salienta a importância de pensar a experiência como algo primordial para a infância, visto que, a criança atribui sentido e significado para aquele brincar e a partir disso, o professor pode exercer seu papel como mediador desse conhecimento, o que contradiz com a perspectiva de um currículo burocratizado e desvinculado da realidade do aluno. 
Corroboramos com Mello et al (2016), para o qual os campos de experiência “pré-definidos" pela BNCEI podem ter efeito limitador sobre as vivências e experiências, visto que, compreendemos a infância como expressão de sentimentos, relações, sentidos e significados do momento e do mundo vivido da criança. E por isso, ressaltamos o pensamento de que a EI não pode ser uma preparação para o ensino fundamental, pois é um período específico com funções distintas e aprendizagens diversificadas por meio de livres experiências que precisam ser preservadas.

Os documentos atuais ainda veem a criança como uma forma fragmentada e expressamos, nesse texto, concordância com Sayão (1999), de que é preciso olhar a criança na sua totalidade e não enquadradas em áreas do conhecimento e alocadas em disciplinas. Por isso, definir os meios de aprendizagem e experiência é também reduzir os espaços de conhecimento.

Ressaltamos a necessidade de que a criança possa atuar de modo a exercitar sua autonomia e criatividade nesse processo chamado brincar. É um momento dela consigo, com o espaço, com os outros e com os materiais. Ou seja, é prioritário seguir as crianças e não os planos (MALAGUZZI, 2001). Nesse sentido, o trabalho pedagógico com a EI deve estar mais voltado à observação e ao diálogo a fim de problematizar situações que possam surgir nas ações daquele brincar e não no sentido de induzir o seu fazer.

Iniciando a Unidade III - Corpo e movimento e as experiências de brincar: da visão adultocêntrica à cultura de pares, foram disponibilizados vídeos com palestras/conversas com diferentes educadores(as) e pesquisadores(as) que tem como tema o brincar, as crianças, a infância. Com isso, buscamos oportunizar a ampliação do olhar para a criança e a infância e possibilidades para repensar o brincar. Os vídeos disponibilizados foram: Um olhar para o brincar - com Renata Meirelles e David Reeks; $A$ voz da criança - com Adriana Friedmann; O tempo da criança - com Luiza Lameirão; Criança e Natureza Gandhy Piorski. Na mesma unidade, a convidada para ministrar o encontro foi a $\operatorname{Prof}^{\mathrm{a}} \operatorname{Dr}^{\mathrm{a}}$ Raquel Firmino Magalhães Barbosa, que nos trouxe reflexões a partir dos textos lidos na unidade, permitindo uma interação dialógica entre os participantes, enriquecendo ainda mais as trocas de experiências e compreensões do tema abordado, nos permitindo compreender mais sobre as brincadeiras lúdicoagressivas.

Antecedendo ao encontro com a convidada, foram disponibilizados dois textos e uma pesquisa da autora. As produções apresentam análises sobre as brincadeiras lúdica-agressivas na EI, desconstruindo o caráter pejorativo a elas atribuído. Um dos artigos aborda a brincadeira de luta como alguma disputa ou confronto, de natureza simbólica e corporal, evidenciando a prevalência de elementos lúdicos juntamente 
com a busca de excitação, de poder, de combate, de nonsense e de transformação" (BARBOSA, MARTINS, MELLO, 2017).

Os mesmos autores alertam ao fato de que, ao olhar adulto, esse tipo de brincadeira costuma ser visto como nocivo e inapropriado para o ambiente escolar, sendo geralmente proibidas. Muitas vezes, os professores intervêm em determinadas brincadeiras a serem realizadas pelas crianças por pensarem que estas não são "brincadeiras de criança", quando na verdade, falta ao professor um olhar mais atento às crianças e as suas brincadeiras. Por vezes revelam experiências vividas ou formas de reinterpretação do que veem em diferentes filmes e desenhos. Os autores destacam, ainda, a complexidade presente nas brincadeiras lúdico-agressivas exigindo, portanto, um olhar cuidadoso e sensível por parte do adulto (BARBOSA, MARTINS, MELLO, 2017).

Finalizando a Unidade III, as professoras receberam uma atividade propondo a elaboração de um relato sobre suas práticas docentes, com objetivo de dar continuidade ao processo de escrita, em direção a uma reflexão sobre a prática docente. Constatamos que as professoras possuem significativas experiências com o brincar, repercutindo na maneira como percebem e mediam as brincadeiras em sua prática docente.

Como culminância da formação continuada, ocorreu o seminário virtual, cujas participantes sistematizaram e compartilharam entre os pares a produção de conhecimento e reflexões adquiridas durante o processo. No decorrer do evento, as professoras compartilharam registros produzidos durante a formação, articulando-os às experiências pedagógicas vividas na docência com a EI.

\section{Considerações Finais}

O exercício de análise do processo vivenciado na realização da formação continuada com professoras de turmas de Educação Infantil de Escolas Municipais de Ensino Fundamental de Santa Maria - RS nos exigiu revisitarmos as ações realizadas e seus desdobramentos, particularmente nos encontros entre integrantes do Grupo Pátio, quando avaliávamos cada etapa e projetávamos a continuidade da caminhada.

A experiência de projetar e realizar uma formação inteiramente em ambiente virtual mostrou-se desafiadora e, ao longo do processo, possibilitou análises e aprendizagens significativas, particularmente em relação a aspectos metodológicos. Não projetamos a formação com a intenção de uma pesquisa sobre as narrativas das professoras, o que nos impediu de produzirmos um texto que tratasse desse conteúdo. 
Não obstante, o processo de análise e diálogo que se estabeleceu entre integrantes do grupo e as professoras, por meio das narrativas, mostrou-se muito profícuo para todos os(as) envolvidos(as).

O envolvimento de cada uma no processo esteve balizado pelas próprias biografias de cada membro do grupo e seu momento no percurso formativo. Mesmo que todos(as) estivessem compartilhando o mesmo processo e, em grande medida, tarefas similares, a forma como cada um(a) experienciou isso foi única. Compartilhamos, fundamentalmente, o diálogo com as professoras participantes, suas experiências pessoais e profissionais, provocando-nos a pensar nosso próprio percurso formativo, considerando-se que nos encontramos em fases distintas, que compreendem desde a graduação até a docência universitária, incluindo mestrandos(as) que atuam com EF em turmas de EI.

A riqueza do diálogo se encontra, exatamente, na diversidade e, por outro lado, no exercício de nos deslocarmos do lugar da EF, conhecido e talvez confortável para nós, para podermos compreender o brincar e as experiências corporais na EI a partir das professoras, em sua maioria pedagogas, e seu trabalho pedagógico com as crianças. A leitura das narrativas converteu-se em um "exercício de escuta" das vozes dessas professoras suas memórias de infância, corpo e movimento, articulando-as com suas experiências profissionais. Resultou desse processo a experiência de buscar alteridade e uma interlocução respeitosa e fecunda.

A própria variação na participação nos desafia a avaliar o formato utilizado e a pensar sobre como as professoras responderam às provocações e desafios que foram colocados em prol da busca por este conhecimento com mudança de comportamento, passando de espectadoras para protagonistas do processo. De outra parte, instiga-nos a pensar novas propostas de formação que impliquem o uso da escrita, decorrente de um movimento de introspecção e de olhar para a própria história de vida.

O processo de produção de narrativas demanda atenção ao tempo interior de cada autor(a), no caso as professoras e, de outra parte, dedicação em sua elaboração. Foi possível observar que o ano de 2020 foi marcado por situações que alteraram profundamente a vida das pessoas, de modo geral. As professoras que participaram da formação foram alvo de muitas outras atividades de formação, desde ações mais voltadas à instrumentalização para o uso de tecnologias educacionais remotas até palestras e rodas de conversas sobre temas ligados à educação infantil. Narrar a experiência do brincar e de experiências pedagógicas com a EI exatamente em um período de distanciamento do cotidiano presencial das escolas foi um desafio que nem sempre logrou êxito. Ainda que a proposta, em grande medida, tenha sido mobilizar memórias, escrever sobre experiências corporais e o brincar, associando com as experiências pedagógicas com as crianças pode ter se tornado um exercício de abstração, distante do mundo vivido. 
Em virtude dos fatos mencionados, salientamos que os integrantes do Grupo Pátio, por meio da participação nesta formação continuada, em especial na interlocução com as professoras, no processo de retorno às suas narrativas, chegaram a reflexões e indagações que repercutiram e ainda reverberam em reuniões do grupo, provocando o pensamento de novos estudos e novas pesquisas. Portanto, essas mediações, resultaram em contribuições importantes para o percurso formativo dos integrantes do grupo, através das interações estabelecidas com as professoras das escolas e os palestrantes convidados e cabe ressaltar que os protagonistas deste processo foram o diálogo e a troca de experiências.

\section{Referências}

BARBOSA, R.F.M.; MARTINS, R.L.R.; MELLO, A.S. Brincadeiras lúdico-agressivas: Tensões e possibilidades no cotidiano na educação infantil. Movimento 2017;23(1):159-170.

BOLIVAR, A. Profissão professor: o itinerário profissional e a construção da escola. Bauru, SP: EDUSC, 2002.

CÔCO, V. A dimensão formadora das práticas de escrita de professores. Curitiba, PR: CRV, 2014.

CAPARRóZ, F. E. Memória Profissional I. 2009. (Desenvolvimento de material didático ou instrucional - Fascículo). Núcleo de Educação Aberta e à Distância - Universidade Federal do Espírito Santo.

CONSTANTINO, N. S. de. Teoria da História e reabilitação da oralidade: convergências de um processo. In: ABRAHÃO, Maria Helena Menna Barreto (Org.). A aventura (auto) biográfica: teoria e empiria. Porto Alegre: EDIPUCRS, 2004. p. 11-27.

COSTA, A.R.; KUNZ, E. O "brincar e se-movimentar" como base teórico-filosófica para a compreensão do ser criança. In: HERMIDA, J.F.; BARRETO, S.J. (Orgs.) Educação Infantil: temas em debate. João Pessoa, PB: Editora Universitária da UFPB, 2013

DALTRO, M.R.; FARIA, A.A. Relato de experiência: Uma narrativa científica na pós-modernidade. Estudos e Pesquisas em Psicologia, Rio de Janeiro, v. 19, n. 1,p. 224, Janeiro a Abril de 2019.

DORNELLES, L. V. Na escola infantil todo mundo brinca se você brinca. In: CRAIDY, C.M.; KAERCHER, G.E.P.S. (Orgs.) Educação infantil: pra que te quero? Porto Alegre, RS: Artmed, 2001.

JOSSO, M. C. Experiências de vida e formação. São Paulo: Cortez, 2004.

JOSSO, M.C. Caminhar para si. Porto Alegre: EDIPUCRS, 2010.

KUNZ, E.; COSTA, A.R. A imprescindível e vital necessidade da criança: "Brincar e Se-Movimentar". In: KUNZ, E. Brincar e se-movimentar: tempos e espaços de vida da criança. Ijuí: Ed. Unijuí, 2015, p. 13-38.

MALAGUZZI, L. La educacion infantil em Reggio Emilia. Barcelona: Octaedro/Rosa Sensar, 2001. 
MARQUES, M.O. A formação do profissional da educação. Ijuí: Ed. UNIJUÍ, 1992.

MELLO et al. A Educação infantil na Base Nacional Comum Curricular: pressupostos e interfaces com a Educação Física. Motrivivência. V.28, n.48, p.130-149, 2016.

SAYÃO, D.T. Educação Física na educação infantil: riscos, conflitos e controvérsias. Motrivivência. Florianópolis, n. 13, p. 221-238, 1999.

SAYÃO, D.T. Corpo e movimento: notas para problematizar algumas questões relacionadas à educação infantil e à educação física. Revista Brasileira de Ciências do Esporte, Campinas, v. 23, n. 2, p. 55-67, jan. 2002.

SIMIANO, L. P; SIMÃO, M. B. Base Nacional Comum Curricular para a Educação Infantil: entre desafios e possibilidades dos campos de experiência educativa. Rev. Cient. n. 41, p. 77-90, 2016.

SOUZA, E. C. de. A arte de contar e trocar experiências: reflexões teórico-metodológicas sobre história de vida em formação. In: Revista Educação em Questão. v. 25, n. 11, 2006, jan./abr., p. 22-39, Natal, RN: EDUFRN. Disponível em: 〈http://www.revistaeduquestao.educ.ufrn.br/pdfs/v25n11.pdf>. Acesso em: 10 fev. 2021.

STAVISKI, G.; SURDI, A.; KUNZ, E. Sem tempo de ser criança: a pressa no contexto da educação de crianças e implicações nas aulas de educação física. Revista Brasileira de Ciências do Esporte. Florianópolis, v. 35, n. 1, p. 113-128, jan./mar. 2013

\section{Como citar este artigo}

EICH, A. B.; PICOLOTTO, J.; CAMARGO, M. C.S. Formação continuada com professores de educação infantil de escolas municipais de ensino fundamental de Santa Maria: o brincar e as experiências corporais. Revista Kinesis, Santa Maria, v. 39, p.01-12, 2021.

* O presente trabalho não contou com apoio financeiro de nenhuma natureza para sua realização. 